\title{
The effect of pyridoxine supplementation on quality of life of patients with chronic lymphocytic leukaemia
}

\author{
*Nwannadi I.A. ${ }^{1}$, Onoja M.A. ${ }^{1}$, Anike U.S. ${ }^{2}$, Aba I.H. ${ }^{1}$, Okoli R ${ }^{1}$, Okolie I. ${ }^{3}$, Aondover M. ${ }^{1}$, \\ Kyoive E. ${ }^{3}$, Alao O.O. ${ }^{1}$
}

\begin{abstract}
Objective: Pyridoxine, is essential in the metabolism of many classes of food, we aimed at determining the effect of its supplementation on the quality of life (QoL) of patients with chronic lymphocytic leukaemia (CLL).

Methods: This study compared the (QoL) and haematological parameters of CLL patients before and after the administration of pyridoxine. Data obtained were analyzed using SPSS version 19.

Results: There was improvement in the QoL of the patients after pyridoxine supplementation; Majority of the parameters that make up the physical functional scales was significantly higher after pyridoxine supplementation. There were also significant improvements in insomnia, appetite loss and constipation after pyridoxine supplementation.
\end{abstract}

Conclusion: Pyridoxine supplementation in patients with CLL marginally improved quality of life.

Keywords: Pyridoxine, Supplementation, Quality of life, Leukaemia, CLL

\footnotetext{
*Correspondence author

Nwannadi I.A.

http://orcid.org/0000-0002-1547-5346

Email:inwannadi@yahoo.co.uk
}

${ }^{1}$ Department of Haematology, Faculty of Basic and Allied Medical Sciences, College of Health Sciences, Benue State University, Makurdi, Nigeria.

${ }^{2}$ Department of Haematology, Federal Medical Centre, Makurdi, Nigeria.

${ }^{3}$ Department of Haematology, Benue State University Teaching Hospital, Makurdi, Nigeria. 


\title{
Effet de la supplémentation en pyridoxine sur la qualité de vie des patients atteints de leucémie lymphoïde chronique
}

\author{
*Nwannadi I.A. ${ }^{1}$, Onoja M.A. ${ }^{1}$, Anike U.S. ${ }^{2}$, Aba I.H. ${ }^{1}$, Okoli R ${ }^{1}$, Okolie I. ${ }^{3}$, Aondover M. ${ }^{1}$, \\ Kyoive E. ${ }^{3}$, Alao O.O. ${ }^{1}$
}

\begin{abstract}
Abstrait
Objectif: La pyridoxine, essentielle au métabolisme de nombreuses classes d'aliments, nous avons cherché à déterminer l'effet de sa supplémentation sur la qualité de vie des patients atteints de leucémie lymphoïde chronique (LLC).
\end{abstract}

Méthodes: Cette étude a comparé les paramètres (qualité de vie) et hématologiques des patients atteints de LLC avant et après l'administration de pyridoxine. Les données obtenues ont été analysées avec SPSS version 19.

Résultats: La qualité de vie des patients s'est améliorée après la supplémentation en pyridoxine; La majorité des paramètres constituant les échelles physiques et fonctionnelles était significativement plus élevée après la supplémentation en pyridoxine. Il y avait aussi des améliorations significatives dans l'insomnie, la perte d'appétit et la constipation après une supplémentation en pyridoxine.

Conclusion: La supplémentation en pyridoxine chez les patients atteints de LLC a légèrement amélioré la qualité de vie.

Mots-clés: pyridoxine, supplémentation, qualité de vie, leucémie, LLC

\footnotetext{
* Auteur de la correspondance

Nwannadi I.A.

http://orcid.org/0000-0002-1547-5346

Email: inwannadi@yahoo.co.uk

${ }^{1}$ Department of Haematology, Faculty of Basic and Allied Medical Sciences, College of Health Sciences, Benue State University, Makurdi, Nigeria.

${ }^{2}$ Department of Haematology, Federal Medical Centre, Makurdi, Nigeria.

${ }^{3}$ Department of Haematology, Benue State University Teaching Hospital, Makurdi, Nigeria.
} 


\section{INTRODUCTION}

Pyridoxine is a vitamin that is essential in the metabolism of protein, carbohydrates, fatty acids, and several other substances, including brain amines (1), where as chronic lymphocytic leukaemia (CLL) is a blood cancer that affects mainly the elderly. Pyridoxine's benefit in patients with tuberculosis has been established as it is known to prevent the development of peripheral neuropathy during isoniazid therapy. Chronic lymphocytic leukaemia is the commonest form of leukaemia in adults in Nigeria (2). Low emotional wellbeing score for CLL patients has been reported compared to the general population and with patients with other forms of cancers (3). The use of chemotherapy alone in the treatment of CLL has not improved on these parameters significantly (4), therefore there is the need to search for agents that could improve the QoL of this group of patients.

Pyridoxine is a compound that has vitamin B6 activities. Large proportions of the naturally occurring pyridoxine are not bioavailable as they occur in glycosylated poorly absorbable form. It performs a wide range of activities especially as a co-enzyme assisting in many metabolic activities amongst which are metabolism of carbohydrate and lipid. Pyridoxine acts by converting tryptophan to niacin or serotonin, breaking down of glycogen to glucose-1-phosphate, conversion of oxalate to glycine, synthesis of gamma aminobutyric acid (GABA) within the CNS, and synthesis of heme necessary for the production of red blood cells.

As stated earlier, pyridoxine has been found to be very useful in preventing polyneuropathy in tuberculosis patients that are on isoniazid (1). It is also useful in reducing pains and may therefore be useful in improving the QoL of patients with CLL in whom pain is one of the major contributors to poor quality of life (5). It has been revealed that there is a $60 \%$ increase in daily requirement of pyridoxine in physiologic states with increased metabolic activities like pregnancy, lactation and exercise (6). Since one of the cardinal features of CLL is increased metabolism (hypermetabolic state), pyridoxine may be of great value in this condition. Investigations of the benefit of vitamins in various medical conditions have been going on. An example was a study in children with malaria which showed improved haematological indices on those that had vitamin A supplementation during treatment (7). Rich sources of pyridoxine include beef liver, fish, and starchy vegetable, and because of prevalent poor economy, most of the patients may not be able to afford these food items and may therefore be deficient of this vital vitamin.

We therefore aim to determine the beneficial effect or otherwise of pyridoxine supplementation (an important coenzyme) in CLL patients, an agent which is of immense benefit to patients with tuberculosis.

\section{MATERIALS AND METHODS}

This was a longitudinal study that sought to determine the impact of pyridoxine supplementation on the quality of life and on the haematological parameters of CLL patients in Makurdi north-central, Nigeria. Ethical clearance for th i s s t u d y refere n c e d $\mathrm{BSUTH} / \mathrm{MKD} / \mathrm{HREC} / 2013 \mathrm{~B} / 2018 / 0019$ (Appendix A) was obtained from the Health Research and Ethics Committee of the Benue State University Teaching Hospital, Makurdi. The study population comprised chronic lymphocytic leukaemia patients that attended the outpatient clinic of the Benue State University Teaching Hospital, (BSUTH) Makurdi and the Federal Medical Centre, (FMC) Makurdi within the period of the study (January-August 2018).

The sample size was calculated using the formula developed by Xavier et al (8) for longitudinal studies. The calculated minimum sample size was 50 . An additional 50 patients were recruited to make up for those that would be lost to follow up. Participants were recruited from the Haematology out-patient clinic of the BSUTH, Makurdi and FMC, Makurdi. They were recruited consecutively as they presented for routine consultations, until a total of 100 participants was reached.

Exclusion criteria included: Objection to participate in the study, patients less than 18 years of age and patients with diagnosis other than CLL. Immediately after the details of the study were explained to the participants and their consent obtained, the EORTC (version 3) quality of life questionnaires (QLQ-C30) were issued to them, and baseline samples for complete blood count were collected. The questionnaires were administered by the research assistant, who also guided the participants in filling them.

The EORTC (version 3) Quality of life questionnaire (QLQ-C30) is a 30-item Likerttype validated questionnaire, which has the advantage of self-administration to respondents. This questionnaire was field-tested in a crosscultural sample of cancer patients in 13 countries to confirm the hypothesized scale structure, to establish reliability and to evaluate validity (8). It 
demonstrated internal consistency for the group under study with a calculated Cronbach alpha of 0.73 in a pilot study. A high score for a functional scale represents a high / healthy level of functioning, a high score for the global health status / QoL represents a high QoL, but a high score for a symptom scale / item represents a high level of symptomatology / problems.

On completion of the questionnaire, $2 \mathrm{ml}$ of venous blood was withdrawn from the cubital vein using a $5 \mathrm{ml}$ syringe and observing aseptic procedures. The blood was dispensed into an EDTA bottle for analysis of haematological parameters. These parameters included red blood cell count, haematocrit (HCT), mean corpuscular volume (MCV), mean corpuscular haemoglobin $(\mathrm{MCH})$, mean corpuscular haemoglobin concentration (MCHC), white blood cell count, differential leukocyte count, and platelet count using the Sysmex haematology auto-analyzer (Sysmex Corporation of America) at the Haematology laboratory of BSUTH, Makurdi. These tests were done within 24 hours after collection. The performance of the auto-analyzer was validated using quality control samples which were run with each batch of the sample specimen and by manual counts. Participants were there after given supplemental tablets of pyridoxine at a dose of $25 \mathrm{mg}$ daily to be taken in addition to their chemotherapy for a period of four months. The participants were mainly on a combination of chlorambucil and prednisolone for varying number of cycles depending on their responses. The pyridoxine was sourced from pharmaceutical outlets where the researchers had no conflict of interests. At the end of this period, the questionnaires were re-administered and their full blood count taken again for comparison.

Data obtained from these analyses were analyzed by the statistical package for social sciences version 19 . The differences in quality of life and haematological indices were tested for significance using the student t-test.

\section{RESULTS}

A total of 100 (one hundred) chronic lymphocytic leukaemia patients were recruited, but 74 (seventy-four) completed the study. Fiftyone were males while 23 were females, translating to a male to female ratio of 2.2: 1 . The mean age of the participants was $62 \pm 8.5$ years. Majority $(66.2 \%)$ of the participants had late stages (stages III and IV) of the disease. Table 1

The quality of life (QoL) of the participants prior to pyridoxine administration was significantly lower than the published data in the EORTIC QLQ-C30 reference value manual (10). All the parameters in the functional scale were significantly lower in our study compared to the reference values. In the symptom scales, our participants were worse off with fatigue, pain and financial difficulty but fared better with nausea, vomiting, dyspnoea, insomnia appetite loss, constipation and diarrhea. Table 2 .

There was improvement in the global health status of the patients after pyridoxine supplementation; however, this was not statistically significant, but majority of the parameters that make up the physical functional scales (Physical functioning, role functioning, emotional functioning and cognitive functioning) was significantly higher after pyridoxine supplementation. Result also showed statistically significant improvements in symptoms after pyridoxine supplementation except for fatigue, Nausea, vomiting and financial difficulties. Table 3. The total white cell count, lymphocyte count and granulocyte count were significantly lower after pyridoxine supplementation and chemotherapy while the haemoglobin concentration and the platelet count were significantly higher after supplementation. Table 4.

\section{DISCUSSION}

The quality of life (QoL) of the participants in our study prior to pyridoxine administration was significantly lower than published data in the EORTIC QLQ-C30 reference value manual (10). The low QoL in our participants may be related to late presentation of our patients which is demonstrated by the high number $(66.2 \%)$ that had the late stages (Ria III and IV) of the disease compared to those used for calculating the reference values mainly stages I and II. It may also be as a result of fewer numbers of participants in our study (74) as compared to 23,555 used for the calculating the reference range or it could be the effect of geographical and racial influences on the quality of life of this category of patients. The above adduced concerns will require further studies. The low QoL from our study was however in keeping with the report of other studies $(4,10,11,12,13)$ around the globe which demonstrated that the different dimensions of QoL were deteriorated by haematological malignancies and, probably, by the side effects of their treatments. Our result revealed that all the parameters in the functional scales of the QoL questionnaire were significantly lower compared to the reference values. This implied that the functional aspect of quality of life of our patients was worse affected 
than the symptom aspect. In the symptom scales, our participants had higher scores for fatigue, pain, and financial difficulties but there were not statistically significant. This implied that our participants had worse symptoms (fatigue, pain and financial difficulties) compared to the reference range and this is in keeping with the fact that our participants presented with the late stages of the disease. We however recorded significantly milder symptoms in the rest of the parameters (dyspnoea, insomnia, appetite loss, constipation, and diarrhoea).

There was marginal improvement in the global health status of our patients after pyridoxine supplementation; but this was not statistically significant. However, parameters in the functional scales revealed that physical functioning, role functioning, emotional functioning and cognitive functioning were significantly higher after pyridoxine supplementation. Researchers had earlier reported a decline in QoL especially when patients were undergoing chemotherapy $(14,15)$. The improved QoL of our patients after pyridoxine supplementation may be an indication that pyridoxine is beneficial in this group of patients. This finding is however contrary to what Jannique et al (16) discovered while working on the effect of vitamin B supplementation on quality of life in communitydwelling adults with mild cognitive impairment. Although pyridoxine deficiency has been noted to lead to increased circulating homocysteine, which is a risk factor for neuropsychiatric disorders including seizures, migraine, chronic pain and depression, Malouf et al (17) in a systematic review revealed no evidence for shortterm benefit from pyridoxine in improving mood (depression, fatigue and tension symptoms) or cognitive functions.

Our result also showed statistically significant improvements in insomnia and appetite loss after pyridoxine supplementation. Although vitamins have not been reported to have soporific effects, B vitamins have been advanced as preventive for insomnia based on research that suggests deficiencies in vitamin B6 promote psychological distress and ensuing sleep disturbance (18) and report by Morin et al (19) earlier indicated that vitamin intakes improve sleep. Another study has identified vitamin B complex as a helpful treatment of nocturnal leg cramps (20) and this may improve the sleep quality of the individual. The precise mechanism for this observation was not however clear. The significant improvement in appetite following pyridoxine supplementation in our study is in keeping with what researchers demonstrated in Rex Rabbit where it was discovered that pyridoxine increased food intake significantly and in a dose-dependent manner (21).

Other symptoms (fatigue, nausea and vomiting, and pain) also improved but not significantly after pyridoxine supplementation. Report of mood changes resulting from pyridoxine deficiency and leading to depression, anxiety, irritability and pain is well documented (22-24). These effects were attributed to the fact that pyridoxine is involved in the production of several neurotransmitters especially gamaaminobutyric acid (GABA) and serotonin which help control anxiety, depression and pains. Improvement in fatigue post pyridoxine may be linked to the fact that pyridoxine plays a vital role in haemoglobin-the protein that carries oxygen round the body-synthesis. Besides feeling tired from anemia, pyridoxine deficiency could also potentially contribute to tiredness due to its role in making the sleep-promoting hormone melatonin (25-26).

The total white cell count, lymphocyte count and granulocyte count were significantly lower after pyridoxine supplementation while the haemoglobin concentration and the platelet count were significantly higher after supplementation. The haematological changes cannot be immediately differentiated from the actions of chemotherapeutic agents. A study involving those patients that are off chemotherapy will help in differentiating the two. But the improvements in haemoglobin concentration and platelet count may be attributed to the pyridoxine since it has been established as a necessary factor in the synthesis of heme.

\section{CONCLUSION}

Pyridoxine supplementation in patients with CLL improved the physical functioning, some symptoms, haemoglobin concentration, platelet count and overall quality of life.

\section{REFERENCES}

1. Dixie ES. Pyridoxine supplementation during isoniazid therapy. 1980: Tubercle 61(4):191-196. DOI: 10.1016/0041-3879(80)90038-0

2. Nwannadi IA, Alao OO, Bazuaye GN, Halim NKD, and Omoti CE (2010). "The Epidemiology of Haematological Malignancies at the University Of Benin Teaching Hospital: A Ten-Year Retrospective Study". The Internet $J$ of Epidemiology. 2010; 9:2

3. Shanafelt TD, Bowen D, Venkat C, Slager SL, Zent CS, Kay NE, et al. Quality of life in chronic 
lymphocytic leukemia: an international survey of 1482 patients. Br J Haematol. 2007 ;139(2):255264.

4. Bernhard H, Georg K, Martin K, Dominic N, Barbara S, and Richard G. Quality of life of patients with chronic lymphocytic leukemia: results of a longitudinal investigation over 1 year. Eur J Haematol. 2004; 72(6):381-389

5. American Society of Clinical Oncology. Leukemia - Chronic Lymphocytic - CLL: Symptoms and S igns $(06 / 2016)$. A c cessed a t www.cancer.net/cancer-types/leukemia-chroniclymphocytic-cll/symptoms-and-signs on November 22, 2018

6. Manore MM. Effect of physical activity on thiamine, riboflavin, and vitamin B-6 requirements. Am J Clin Nutr. 2000 Aug;72(2 Suppl):598S-606S. doi: 10.1093/ajcn/72.2.598S.

7. Olayemi SO, Oreagba IA, Alayo AS, Temiye EO, Nwoye E, Bamino BS et al. Vitamin A supplementation as an adjunct in the treatment of mild to moderate childhood malaria. Nig Med Pract 2016;69 (3-4):32-38)

8. Xavier B, Xiaomei L, and Donna S. Power and sample size calculations for longitudinal studies estimating a main effect of a time-varying exposure. Statistical Methods in Medical Research. 2010; (20): 5, 471 - 487

9. Aaronson NK, Ahmedzai S, Bergman B, Bullinger M, Cull A, Duez NJ, et al. The European Organization for Research and Treatment of Cancer QLQ-C30: a quality-of-life instrument for use in international clinical trials in oncology. $\mathrm{J}$ Natl Cancer Inst. 1993 Mar 3;85(5):365-76.

10. Allart-Vorelli P, Porro B, Baguet F, Michel A, and Cousson-Gélie F. Haematological cancer and quality of life: a systematic literature review. Blood Cancer Journal. 2005 (5), 305-309 doi:10.1038/bcj.2015.29

11. Strasser-Weippl K, Ludwig H. Psychosocial QOL is an independent predictor of overall survival in newly diagnosed patients with multiple myeloma. Eur J Haematol 2008; 81: 374-379.

12. Else M, Smith AG, Cocks K, Richards SM, Crofts $\mathrm{S}$, Wade R et al. Patients' experience of chronic lymphocytic leukaemia: baseline health-related quality of life results from the LRF CLL4 trial. Brit J Haematol 2008; 143: 690-697.

13. Vallance JKH, Courneya KS, Jones LW, Reiman T. Differences in quality of life between nonHodgkin's lymphoma survivors meeting and not meeting public health exercise guidelines. Psychooncol 2005; 14:979-991.

14. Von Gruenigen VE, Frasure HE, Grandon M, et al. Longitudinal assessment of quality of life and lifestyle in newly diagnosed ovarian cancer patients: the roles of surgery and chemotherapy. Gynecol Oncol. 2006; 103: 120-126.

15. Von Gruenigen VE, Gil KM, Huang H, et al. Assessment of factors that contribute to decreased quality of life in Gynecologic Oncology Group ovarian cancer trials. Cancer. 2009; 115:
4857-4864.

16. Jannique GZ, Marijke JM, Chin AP, Marijke HR, and Willem VM. The effect of walking and vitamin B supplementation on quality of life in community-dwelling adults with mild cognitive impairment: a randomized, controlled trial. Quality of Life Research. 2007, 16: (7), 1137-1146

17. Malouf R, Grimley Evans J. The effect of vitamin B6 on cognition. Cochrane Database Syst Rev. 2003;(4):CD004393.

18. Baldewicz T, Goodkin K, Feaster DJ, Blaney NT, Kumar M, Kumar A, et al. Plasma pyridoxine deficiency is related to increased psychological distress in recently bereaved homosexual men. Psychosom Med. 1998; 60(3):297-308.

19. Morin CM, Koetter U, Bastien C, Ware JC, and Wooten V. Valerian-hops combination and diphenhydramine for treating insomnia: a randomized placebo-controlled clinical trial. Sleep. 2005 Nov; 28(11):1465-71

20. Chan P, Huang TY, Chen YJ, Huang WP, and Liu YC. Randomized, double-blind, placebocontrolled study of the safety and efficacy of vitamin B complex in the treatment of nocturnal leg cramps in elderly patients with hypertension. J Clin Pharmacol. 1998 ; 38(12):1151-1154.

21. G. Liu, and Zhao N. Effects of Dietary Vitamin B6 Supplemental Level on Growth Performance and Vitamin B6 Metabolism of Growing Rex Rabbits. Chinese Journal of Animal Nutrition, 27, 2292 2299.

22. Sato K. Why is vitamin B6 effective in alleviating the symptoms of autism? Med Hypotheses. Epub $2018 ; 115: 103-106$. d o i : 10.1016/j.mehy.2018.04.007.

23. Koleini S, and Valiani M. Comparing the Effect of Auriculotherapy and Vitamin B6 on the Symptoms of Premenstrual Syndrome among the Students who Lived in the Dorm of Isfahan University of Medical Sciences.Iran J Nurs Midwifery Res. 2017 Sep-Oct;22(5):354-358. doi: 10.4103/ijnmr.IJNMR_120_16.

24. Retallick-Brown H, Rucklī̄ge J, and Blampied N. Study Protocol for a Randomized Double Blind, Treatment Control Trial Comparing the Efficacy of a Micronutrient Formula to a Single Vitamin Supplement in the Treatment of Premenstrual Syndrome. Medicines (Basel). 2016 Dec 7;3(4). pii: E32. doi: 10.3390/medicines3040032.

25. Erland LA, and Saxena PK. Melatonin Natural Health Products and Supplements: Presence of Serotonin and Significant Variability of Melatonin Content. J Clin Sleep Med. 2017 Feb 15;13(2):275-281. doi: 10.5664/jcsm.6462.

26. Volpe AD, Lucia A, Pirozzi C, Pastore V. Comparative Study between the use of Melatonin and A Solution with Melatonin, Tryptophan, and Vitamin B6 as an Inducer of Spontaneous Sleep in Children During an Auditory Response Test: An Alternative to Commonly Used Sedative Drugs. J Int Adv Otol. 2017 Apr;13(1):69-73. doi: 10.5152/iao.2017.3054. Epub 2017 Mar 9 
Table 1: Socio-demographic characteristics of the participants

\begin{tabular}{lc}
\hline Socio-demographic variables & n (\%) \\
\hline Age (years) & $35(47.3)$ \\
$50-59$ & $24(32.4)$ \\
$60-69$ & $15(20.3)$ \\
$70-79$ & $62 \pm 8.5$ \\
Mean \pm SD & \\
Sex & $51(68.9)$ \\
Male & $23(31.1)$ \\
Female & \\
Educational level & $8(10.8)$ \\
None & $11(14.9)$ \\
Primary & $0(0.0)$ \\
Secondary & $55(74.3)$ \\
Tertiary & \\
Occupation & $41(55.4)$ \\
Unemployed & $14(18.9)$ \\
Civil/Public servant & $19(25.7)$ \\
Self-employed & \\
Ria stage & $25(33.8)$ \\
I and II & $49(66.2)$ \\
III and IV & \\
&
\end{tabular}

Table 2: Comparing quality of life of the participants prior to pyridoxine administration with the EORTIC QLQ-C30 reference values

\begin{tabular}{llll}
\hline Parameters & $\begin{array}{l}\text { Reference } \\
\text { values n(SD) } \\
\mathbf{n = 2 3 , 5 5 3}\end{array}$ & $\begin{array}{l}\text { Scores before } \\
\text { pyridoxine } \\
\text { supplementation } \\
\text { n(SD) } \mathbf{n}=\mathbf{7 4}\end{array}$ & p-value \\
\hline Global health status/QoL & $61.3 \pm 24.2$ & $50.2 \pm 20.3$ & 0.0001 \\
Functional scales & $76.7 \pm 23.2$ & $65.3 \pm 15.4$ & 0.0001 \\
Physical functioning & $70.5 \pm 32.8$ & $59.0 \pm 10.2$ & 0.0001 \\
Role functioning & $71.4 \pm 24.2$ & $60.1 \pm 12.1$ & 0.0001 \\
Emotional functioning & $82.6 \pm 21.9$ & $56.5 \pm 12.6$ & 0.0001 \\
Cognitive functioning & $75.0 \pm 29.1$ & $53.3 \pm 11.4$ & 0.0001 \\
Social functioning & $34.6 \pm 27.8$ & $39.0 \pm 16.8$ & 0.1736 \\
Symptom scales & $9.1 \pm 19.0$ & $8.2 \pm 14.4$ & 0.6839 \\
Fatigue & $27.0 \pm 29.9$ & $34 \pm 17.5$ & 0.0541 \\
Nausea and vomiting & $21.0 \pm 28.4$ & $4.6 \pm 10.5$ & 0.0001 \\
Pain & $28.9 \pm 31.9$ & $10.4 \pm 5.7$ & 0.0001 \\
Dyspnoea & $21.1 \pm 31.3$ & $9.3 \pm 6.9$ & 0.0013 \\
Insonmia & $17.5 \pm 28.4$ & $9.5 \pm 4.3$ & 0.0154 \\
Appetite loss & $9.0 \pm 20.3$ & $1.1 \pm 0.7$ & 0.0008 \\
Constipation & $16.3 \pm 28.1$ & $21.9 \pm 14.3$ & 0.0866 \\
Diarrhoea & & & \\
Financial difficulties & &
\end{tabular}

QoL= quality of life 
Table 3: Quality of life of the participants before and after pyridoxine supplementation

\begin{tabular}{llll}
\hline Parameters & $\begin{array}{l}\text { Scores } \\
\text { pyridoxine } \\
\text { supplementation } \\
\text { n(SD) } \\
\mathbf{n = 7 4}\end{array}$ & $\begin{array}{l}\text { Scores } \\
\text { pyridoxine } \\
\text { supplementation } \\
\text { n(SD) } \\
\text { n=74 }\end{array}$ & \\
& $50.2 \pm 20.3$ & $52.1 \pm 19.3$ & 0.5604 \\
\hline Global health status/QoL & & & \\
Functional scales & & $75.0 \pm 21.2$ & 0.0018 \\
Physical functioning & $65.3 \pm 15.4$ & $66.7 \pm 12.6$ & 0.0001 \\
Role functioning & $59.0 \pm 10.2$ & $68.0 \pm 14.2$ & 0.0004 \\
Emotional functioning & $60.1 \pm 12.1$ & $66.7 \pm 13.4$ & 0.0001 \\
Cognitive functioning & $56.5 \pm 12.6$ & $52.1 \pm 18.2$ & 0.6315 \\
Social functioning & $53.3 \pm 11.4$ & & \\
Symptom scales & $39 \pm 16.8$ & $36 \pm 15.7$ & 0.2636 \\
Fatigue & $8.2 \pm 14.4$ & $6.3 \pm 12.4$ & 0.3911 \\
Nausea and vomiting & $34 \pm 17.5$ & $31 \pm 20.3$ & 0.3372 \\
Pain & $4.6 \pm 10.5$ & $4.7 \pm 12.0$ & 0.9570 \\
Dyspnoea & $10.4 \pm 5.7$ & $7.3 \pm 4.1$ & 0.0002 \\
Insonmia & $9.3 \pm 6.9$ & $6.2 \pm 2.4$ & 0.0004 \\
Appetite loss & $9.5 \pm 4.3$ & $7.3 \pm 6.5$ & 0.0164 \\
Constipation & $1.1 \pm 0.7$ & $1.2 \pm 0.4$ & 0.2877 \\
Diarrhoea & $21.9 \pm 14.3$ & $23 \pm 12.2$ & 0.6154 \\
Financial difficulties & & & \\
\hline
\end{tabular}

Table 4: Haematological parameters of participants before and after pyridoxine supplementation and chemotherapy

\begin{tabular}{lccc}
\hline Parameter & $\begin{array}{l}\text { Before } \\
\text { pyridoxine } \\
\text { supplementation } \\
\text { (mean } \pm \text { SD) }\end{array}$ & $\begin{array}{l}\text { After pyridoxine } \\
\text { supplementation } \\
\text { (mean } \pm \text { SD) }\end{array}$ & p-value \\
\hline $\mathrm{TWBC}\left(\mathrm{x} 10^{9} / \mathrm{L}\right)$ & $46.0 \pm 43.6$ & $23.5 \pm 15.6$ & 0.0001 \\
$\mathrm{Lym}\left(\mathrm{x} 10^{9} / \mathrm{L}\right)$ & $33.0 \pm 37.3$ & $18.2 \pm 9.4$ & 0.0013 \\
$\mathrm{Gr}\left(\mathrm{x} 10^{9} / \mathrm{L}\right)$ & $6.9 \pm 4.7$ & $5.4 \pm 2.1$ & 0.0139 \\
$\mathrm{Hb}(\mathrm{g} / \mathrm{dL})$ & $9.0 \pm 1.8$ & $10.1 \pm 0.9$ & 0.0001 \\
$\mathrm{MCV}(\mathrm{fL})$ & $95.0 \pm 12.7$ & $96.0 \pm 13.4$ & 0.6442 \\
$\mathrm{MCH}(\mathrm{pg})$ & $28.5 \pm 1.9$ & $28.7 \pm 1.2$ & 0.4480 \\
$\mathrm{MCHC}(\mathrm{g} / \mathrm{dL})$ & $30.1 \pm 2.4$ & $29.4 \pm 1.7$ & 0.0330 \\
$\mathrm{Platelet}\left(\mathrm{x} 10^{9} / \mathrm{L}\right)$ & $143.4 \pm 63.8$ & $172.1 \pm 54.5$ & 0.0040 \\
$\mathrm{PDW}(\mathrm{fL})$ & $9.0 \pm 2.3$ & $8.7 \pm 1.9$ & 0.3917 \\
$\mathrm{MPV}(\mathrm{fL})$ & $9.9 \pm 1.2$ & $8.7 \pm 0.8$ & 0.0001 \\
\hline
\end{tabular}

Key: TWBC-Total white blood cell count, Lym- lymphocyte count, Gr-Granulocyte count, Hb-Haemoglobin concentration, MCV-Mean cell volume, MCH-Mean cell volume, MCHC-Mean corpuscular haemoglobin concentration, PDW-Platelet distribution width, MPV-Mean platelet volume, 